\title{
IMPLEMENTASI METODE SAW PADA SISTEM PENDUKUNG KEPUTUSAN PENERIMA HIBAH PENELITIAN DAN PENGABDIAN KEPADA MASYARAKAT DOSEN UNA
}

\author{
Harmayani, Budi Armadi \\ Program Studi Teknik Informatika, Universitas Asahan \\ Jl. Ahmad Yani Kisaran, Sumatera Utara \\ baakamik@yahoo.co.id, Budiarmadi11@gmail.com
}

\begin{abstract}
Asahan University is one of the private universities in North Sumatra which has Institution B accreditation in 2019 which is led by the Chancellor Prof. Dr. Ibnu Hajar, M.Sc, Asahan University has a Research and Community Service Institute (LPPM) that regulates the process of conducting research and service of lecturers in Asahan University, but the current problem is that the selection system still uses manual methods by checking data such as whether the uploads research or dedication, looks at proposals submitted by lecturers to LPPM, lecturers' biodata, details of fees, looks at the feasibility of research and service titles. To overcome the current problems in determining the selection of internal grant funding at Asahan University by applying the SAW method calculation algorithm from each of the criteria such as preliminary criteria, literature review criteria, criteria of research and technology research criteria, research method criteria, language criteria and the output criteria from the calculation results is a decision whether or not the lecturer is entitled to get help. From the results of this study, the applications generated are following the existing provisions to overcome the problems that occur at Asahan University LPPM.
\end{abstract}

Keywords - Asahan University, LPPM, Decision Making System, Internal Hibah, Research and Service, SAW Method

Abstrak - Universitas Asahan merupakan salah satu Universitas swasta yang ada di Sumatera Utara yang memiliki akreditasi Institusi B pada tahun 2019 yang di pimpin oleh Rektor Prof. Dr. Ibnu Hajar, M.Si, Universitas Asahan memiliki Lembaga Penelitian dan Pengabdian Masyarakat (LPPM) yang mengatur proses pelaksanaan penelitian dan pengabdian dosen yang ada di lingkungan Universitas Asahan, namun masalah saat ini sistem seleksi masih menggunakan cara manual dengan mengecek data-data seperti apakah dia mengunggah penelitian atau pengabdian, melihat proposal yang diajukan dosen ke LPPM, biodata dosen, rincian biaya, melihat kelayakan judul penelitian dan pengabdian. Untuk mengatasi masalah yang terjadi saat ini pada penentuan seleksi penerimaan dana hibah internal yang ada di Universitas Asahan dengan cara menerapkan algoritma perhitungan metode SAW dari tiap-tiap keriteria seperti kriteria pendahuluan, kriteria kajian pustaka, kriteria ungga ristekdikti, kriteria metode penelitian, kriteria bahasa dan kriteria luaran dari hasil perhitungan didapat suatu keputusan berhak atau tidaknya dosen mendapatkan bantuan. Dari hasil penelitian ini aplikasi yang dihasilkan sesuai dengan ketentuan yang ada untuk mengatasi masalah yang terjadi pada LPPM Universitas Asahan.

Kata Kunci - Universitas Asahan, LPPM, Sistem Pengambilan Keputusan, Hibah Internal, Penelitian dan Pengabdian, Metode SAW

\section{PENDAHULUAN}

Universitas Asahan sudah terakreditasi Institusi B pada tahun 2019 yang di pimpin oleh Rektor Prof. Dr. Ibnu Hajar, M.Si, Universiitas Asahan memiliki 5 Fakultas diantaranya Fakultas Teknik, Fakultas Pertanian, Fakultas Ekonomi, Fakultas Hukum, dan FKIP, tidak hanya itu Universitas Asahan memiliki Dosen-dosen yang tidak kala berkualitasnya dengan Dosen-dosen di Universitas yang ada di Indonesia, bahkan dosen Universitas Asahan sudah banyak yang lulus S3 untuk meningkatkan mutu pengajaran, serta mengingkatkan penelitian dan pengabdian kepada masyarakat, setiap tahunnya dosen Universitas Asahan mengikuti seleksi proposan hibah Ristekdikti dan sebagaian dosen
Universitas Asahan banyak yang mendapatkan hibah penelitian dan pengabdian dari tahun ketahun peningkatan penelitian dan pengabdian dosen semangkin tinggi ditandai dengan tahun 2019 dosen yang mendapatkan dan bantuan Dikti sebanyak 11 penelitian dan 3 pengabdian kepada masyarakat.

Lembaga Penelitian dan Pengabdian Masyarakat (LPPM) Universitas Asahan merupakan lembaga yang mengatur proses pelaksanaan penelitian dan pengabdian dosen yang ada di lingkungan Universitas Asahan, melalui LPPM proses pencairan dana bagi dosen yang mendapatkan hibah DIKTI, tidak hanya itu LPPM Universitas Asahan memiliki program hibah internal penelitian dan pengabdin yang bersumberkan dari dana Yayasan Universitas Asahan tiap tahunnya, untuk membantu dosen-dosen yang 
ingin melakukan penelitian dan pengabdian masyarakat. Untuk mendapatkan dana tersebut LPPM Universitas Asahan melakukan seleksi dari beberapa kriteria yang ditentukan, namun masalah saat ini sistem seleksi masi menggunakan cara manual dengan mengecek data-data seperti apakah dia mengunggah penelitian atau pengabdian, melihat proposal yang diajukan dosen ke LPPM, biodata dosen, rincian biaya, melihat kelayakan judul penelitian dan pengabdian.

Pengambilan keputusan merupakan proses pemilihan alternatif tindakan untuk mencapai tujuan atau sasaran tertentu. Pengambilan keputusan dilakukan dengan pendekatan sistematis terhadap permasalahan melalui proses pengumpulan data menjadi informasi serta ditambah dengan faktor faktor yang perlu dipertimbangkan dalam pengambilan keputusan.

Pada proses perancangan aplikasi ini, diterapkan metode Simple Additive Weighting (SAW) dalam studi kasus penentuan keputusan penerimaan hibah penelitian dan pengabdian kepada masyarakat. Metode SAW merupakan suatu metode dengan cara pembobotan dari rating kinerja pada setiap alternatif pada semua atribut dari kriteria yang ditetapkan. Dari permasalahan diatas, penulis berinisiatif untuk merancang Aplikasi Pendukung keputusan penerimaan hibah penelitian dan pengabdian kepada masyarakat bagi dosen Universitas Asahan. Melalui sistem tersebut diharapkan dapat memberikan layanan yang optimal dan cepat dalam menentukan dosen yang berhak mendapatkan dana bantuan internal.

\section{A. Sistem}

Dalam mendefinisikan sistem terdapat dua kelompok pendekatan sistem, yaitu sistem yang lebih menekankan pada prosedur dan elemennya. Prosedur didefinisikan sebagai suatu urutan-urutan yang tepat dari tahapan-tahapan instruksi yang menerangkan apa yang harus dikerjakan, siapa yang mengerjakan, kapan dikerjakan[1].

\section{B. $\quad M y S Q L$}

Mysql adalah salah satu jenis database server yang sangat terkenal. Kepopulerannya disebabkan MySQL menggunakan SQL sebagai bahasa dasar untuk mengakses databasenya. MySQL bersifat free dengan lisensi GNU General Public License (GPL)[2].

\section{Visual Basic Net 2010}

Visual Studio 2010 merupakan suatu perangkat lunak yang dapat digunakan untuk pengembangan berbagai macam aplikasi yang memiliki berbagai macam tipe antara lain aplikasi desktop (Windows Form, CommandLine (Console)), Aplikasi Web, Windows Mobile (Poket PC). Visual Studio 2010 memiliki lebih dari satu kompiler, SDK
(Software Development Kid), dan Dokumentasi Tutorial (MSDN Library). Kompiler yang dimasukkan kedalam Visual Studio 2010 antara lain Visual Basic, Visual C\#, Visual C++, Visual InterDev, Visual $\mathrm{J}++$,Visual F\#, dan Visual Source Safe, dan banyak yang lainnya. Dan semua itu sudah terpaket dan diperuntukkan kedalam platform .Net Framework 4.0 atau versi yang lebih tinggi[3].

\section{METODOLOGI PENELITIAN}

\section{A. Kerangka Kerja Penelitian}

Penerapan rancangan penelitian dilakukan untuk memperoleh data-data yang dibutuhkan sehingga penyusun dalam penelitian ini dapat di selesaikan dengan baik dan sistematis. Dalam kerangka kerja penelitian yang penulis buat terdiri dari pengumpulan data, studi pustaka, analisis, desain, implementasi dan evaluasi. Untuk lebih jelasnya, kerangka kerja penelitian dapat dilihat pada gambar 1 .

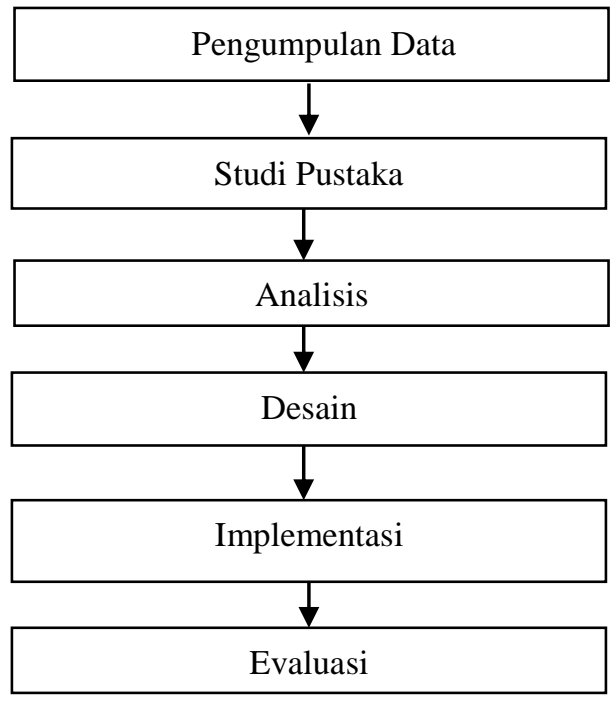

Gambar 1 Kerangka Kerja Penelitian

\section{B. Metode Penelitian}

Penelitian ini merupakan penelitian kualitatif dengan rancangan studi kasus, Pendekatan kualitatif digunakan dalam penelitian ini untuk mendeskripsikan bagaimana penggunaan metode SAW di Lembaga Penelitian Pengabdian Pada Masyarakat (LPPM) Universitas Asahan dalam menentukan Dosen yang berhak menerima dana Hibah internal penelitian dan pengabdian. Tingkat menentukan hibah yang baik sulit untuk diketahui karena banyak faktor yang mempengaruhinya dan metode khusus yang tepat agar penentuannya menjadi sangat akurat sesuai kriteria yang sudah ditentukan. Pada penelitian ini akan mencari alternatif yang terbaik yang berdasarkan kriteria dengan menerapkan metode SAW [4].

Metode ini dipilih karena mampu menyeleksi alternatif yang terbaik dari aspek-aspek kriteria yang ada. Dengan metode SAW ini akan menghasilkan 
rangking yang sesuai dan merekomendasikan. Sistem pendukung keputusan ini nantinya akan berbasis dekstop sehingga akan memudahkan dalam mengakses sehingga dapat membantu pihak LPPM Universitas Asahan dalam pengambilan keputusan.

\section{ANALISA DAN IMPLEMENTASI}

\section{A. Analisa Sistem}

Dalam Analisis sistem yang harus diinputkan yaitu alternatif penerima dana hibah internal penelitian dan pengabdian masyarakat, dimana masing-masing mempunyai kriteria yang terdiri dari kriteria pendahuluan, keriteria kajian pustaka, keriteria ungga hibah ristekdikti, keriteria metode penelitian, keriteria penggunaan bahasa dan keriteria luaran/output, selanjutnya pemberian bobot kriteria dan sub kriterianya yang ditentukan oleh admin, setelah itu dilakukan penginputan nilai dari masingmasing kriteria dan yang terakhir merupakan perhitungan otomatis dari data yang sudah diinputkan, berikut ini contoh perhitungan manual yang diambil dari 3 calon penerima hibah internal pada Tabel 1 sebagai berikut.

Tabel 1 Data Seleksi Hibah Internal Penelitian dan Pengabdian

\begin{tabular}{lll}
\hline No & Alternatif & Nama Alternatif \\
\hline 1 & A1 & Harmayani, ST., M.Kom \\
\hline 2 & A2 & $\begin{array}{l}\text { Muhammad Yasin Simargolang, } \\
\text { M.Kom }\end{array}$ \\
\hline 3 & A3 & Rumondang, S.Pi., M.Pi \\
\hline
\end{tabular}

Tabel 2 Data Kriteria Penilaian Proposal

\begin{tabular}{ccl} 
No & Kriteria & \multicolumn{1}{c}{ Nama Kriteria } \\
\hline 1 & C1 & Kriteria pendahuluan \\
\hline 2 & C2 & Keriteria kajian pustaka \\
\hline 3 & C3 & Keriteria ungga hibah ristekdikti \\
\hline 4 & C4 & Keriteria metode penelitian \\
\hline 5 & C5 & Keriteria penggunaan bahasa \\
\hline 6 & C6 & Keriteria luaran/output \\
\hline
\end{tabular}

Adapun Penentuan dari setiap Kriteria terdiri dari 6 Kategori yaitu:

1. Kriteria Pendahuluan

Tabel 3 Bobot Untuk Keriteria Pendahuluan

\begin{tabular}{|c|c|c|c|}
\hline No & Kriteria & Nilai & Bobot \\
\hline \multirow{4}{*}{1} & \multirow{4}{*}{$\begin{array}{l}\text { Pentingnya } \\
\text { Penelitian }\end{array}$} & Sangat Penting & 3 \\
\hline & & Penting & 2 \\
\hline & & Kurang Penting & 1 \\
\hline & & Tidak Penting & 0 \\
\hline \multirow{3}{*}{2} & \multirow{3}{*}{$\begin{array}{l}\text { Ketajaman } \\
\text { Rumusan } \\
\text { Masalah }\end{array}$} & Sangat Bagus & 3 \\
\hline & & Bagus & 2 \\
\hline & & Kurang Bagus & 1 \\
\hline
\end{tabular}

\begin{tabular}{|c|c|c|c|}
\hline No & Kriteria & Nilai & Bobot \\
\hline & & Tidak Bagus & 0 \\
\hline \multirow{4}{*}{3} & \multirow{4}{*}{$\begin{array}{l}\text { Manfaat } \\
\text { Hasil } \\
\text { Penelitian }\end{array}$} & Sangat Bermanfaat & 3 \\
\hline & & Bermanfaat & 2 \\
\hline & & Cukup Bermanfaat & 1 \\
\hline & & Tidak Bermanfaat & 0 \\
\hline
\end{tabular}

2. Keriteria Kajian Pustaka

Tabel 4 Bobot Untuk Keriteria Kajian Pustaka

\begin{tabular}{|c|c|c|c|}
\hline No & Kriteria & Nilai & Bobot \\
\hline \multirow{3}{*}{1} & \multirow{3}{*}{ Kekomprehensifan } & Komprehensif & 3 \\
\hline & & $\begin{array}{l}\text { Kurang } \\
\text { Komprehensif }\end{array}$ & 1 \\
\hline & & $\begin{array}{l}\text { Tidak } \\
\text { Komprehensif }\end{array}$ & 0 \\
\hline \multirow{2}{*}{2} & \multirow{2}{*}{ Kemuktahiran } & $\begin{array}{l}\text { Perkembangan } \\
\text { Ilmu }\end{array}$ & 3 \\
\hline & & $\begin{array}{l}\text { Tidak Adanya } \\
\text { Perkembangan }\end{array}$ & 1 \\
\hline
\end{tabular}

3. Keriteria Ungga Hibah Ristekdikti

Tabel 5 Bobot Untuk Keriteria Ungga Hibah

Ristekdikti

\begin{tabular}{cclc}
\hline No & Kriteria & \multicolumn{1}{c}{ Nilai } & Bobot \\
\hline \multirow{2}{*}{1} & \multirow{2}{*}{ Proposal } & Unggah & 5 \\
\cline { 3 - 4 } & & Tidak Unggah & 0 \\
\hline
\end{tabular}

4. Keriteria Metode Penelitian

Tabel 6 Bobot Untuk Keriteria Metode Penelitian

\begin{tabular}{cllc}
\hline No & Kriteria & \multicolumn{1}{c}{ Nilai } & Bobot \\
\hline \multirow{2}{*}{1} & $\begin{array}{l}\text { Ketetapan } \\
\text { Metode }\end{array}$ & $\begin{array}{l}\text { Metode sesuai } \\
\text { dengan judul }\end{array}$ & 2 \\
\cline { 3 - 4 } & Metode Tidak Ada & 0 \\
\hline \multirow{2}{*}{2} & $\begin{array}{l}\text { Kejelasan } \\
\text { dan } \\
\text { Kerincian }\end{array}$ & $\begin{array}{l}\text { Alur Metode } \\
\text { Terperinci }\end{array}$ & 3 \\
\cline { 3 - 4 } & Kurang jelas & 1 \\
\cline { 3 - 4 } & & & Metode Tidak Jelas \\
\hline
\end{tabular}

5. Keriteria Penggunaan Bahasa

Tabel 7 Bobot Untuk Keriteria Penggunaan Bahasa

\begin{tabular}{|c|c|c|c|}
\hline No & Kriteria & Nilai & Bobot \\
\hline \multirow{3}{*}{1} & \multirow{3}{*}{ Kebakuan } & Baku & 2 \\
\hline & & Kurang Baku & 1 \\
\hline & & Tidak Baku & 0 \\
\hline \multirow{3}{*}{2} & \multirow{3}{*}{$\begin{array}{l}\text { Kejelasan } \\
\text { Bahasa }\end{array}$} & Bahasa Jelas & 2 \\
\hline & & Kurang Jelas & 1 \\
\hline & & Tidak Jelas & 0 \\
\hline
\end{tabular}

6. Keriteria Luaran/Output

Tabel 8 Bobot Untuk Keriteria Luaran/Output

\begin{tabular}{|c|c|c|c|}
\hline No & Kriteria & Nilai & Bobot \\
\hline \multirow[b]{2}{*}{1} & \multirow[b]{2}{*}{$\begin{array}{l}\text { Pengembangan } \\
\text { IPTEKS }\end{array}$} & Perkembangan & 2 \\
\hline & & $\begin{array}{l}\text { Tidak Ada } \\
\text { Perkembangan }\end{array}$ & 1 \\
\hline \multirow{4}{*}{2} & \multirow{4}{*}{$\begin{array}{l}\text { Publikasi } \\
\text { Luaran }\end{array}$} & Internasional & 3 \\
\hline & & Nasional & 2 \\
\hline & & Lokal & 1 \\
\hline & & Tidak Ada & 0 \\
\hline
\end{tabular}




\begin{tabular}{lllc}
\hline No & Kriteria & \multicolumn{1}{c}{ Nilai } & Bobot \\
\hline \multirow{2}{*}{3} & \multirow{2}{*}{ Seminar } & $\begin{array}{l}\text { Seminar } \\
\text { Internasional }\end{array}$ & 3 \\
\cline { 3 - 4 } & & Seminar Nasional & 1 \\
\hline
\end{tabular}

\begin{tabular}{|c|c|c|c|}
\hline No & Kriteria & Nilai & Bobot \\
\hline & & Tidak Ada & 0 \\
\hline
\end{tabular}

Tabel 9 Data Kriteria dan Seleksi Proposal (Alternatif)

\begin{tabular}{|c|c|c|c|c|c|c|}
\hline \multirow{2}{*}{$\begin{array}{c}\text { Nama } \\
\text { Penerima } \\
\text { Hibah }\end{array}$} & \multicolumn{6}{|c|}{ Kriteria } \\
\hline & Pendahuluan & $\begin{array}{c}\text { Kajian } \\
\text { Pustaka }\end{array}$ & $\begin{array}{l}\text { Ungga } \\
\text { Hibah }\end{array}$ & $\begin{array}{c}\text { Metode } \\
\text { Penelitian }\end{array}$ & $\begin{array}{c}\text { Penggunaan } \\
\text { Bahasa }\end{array}$ & $\begin{array}{c}\text { Luaran/ } \\
\text { Output }\end{array}$ \\
\hline (A1) & 2,33333 & 2 & 0 & 1,5 & 1 & 0,66666 \\
\hline (A2) & 2,66666 & 3 & 5 & 1,5 & 1,5 & 1,33333 \\
\hline (A3) & 2,33333 & 3 & 5 & 2,5 & 1,5 & 1,66666 \\
\hline
\end{tabular}

$\left[\begin{array}{llllll}\mathrm{C} 1-1 & \mathrm{C} 2-1 & \mathrm{C} 3-1 & \mathrm{C} 4-1 & \mathrm{C} 5-1 & \mathrm{C} 6-1 \\ \mathrm{C} 1-2 & \mathrm{C} 2-2 & \mathrm{C} 3-2 & \mathrm{C} 4-2 & \mathrm{C} 5-2 & \mathrm{C} 6-2 \\ \mathrm{C} 1-3 & \mathrm{C} 2-3 & \mathrm{C} 3-3 & \mathrm{C} 4-3 & \mathrm{C} 5-3 & \mathrm{C} 6-3\end{array}\right]$

Rumus Normalisasi Matrik/indek kecocokan :

$$
\mathrm{rij}=\frac{\mathrm{x}_{\mathrm{ij}}}{\operatorname{Max} \mathrm{xij}}
$$

Ket :

rij $\quad=$ indeks kecocokan/ Normalisasi matriks dari alternative

$\mathrm{A}_{\mathrm{i}-\mathrm{j}} \mathrm{xij}=$ Rating fuzzy untuk derajat kecocokan alternative keputusan $\mathrm{A}_{\mathrm{i}-\mathrm{j}} \quad$ terhadap criteria $\mathrm{C}_{\mathrm{ij}}$.

Max Xij = Maximum nilai yang dimiliki oleh semua alternative pada $\mathrm{Ci}-\mathrm{j}$.

Normalisasi Matrix Alternatif 1 (A1/Harmayani, S.T., M.Kom) $=$

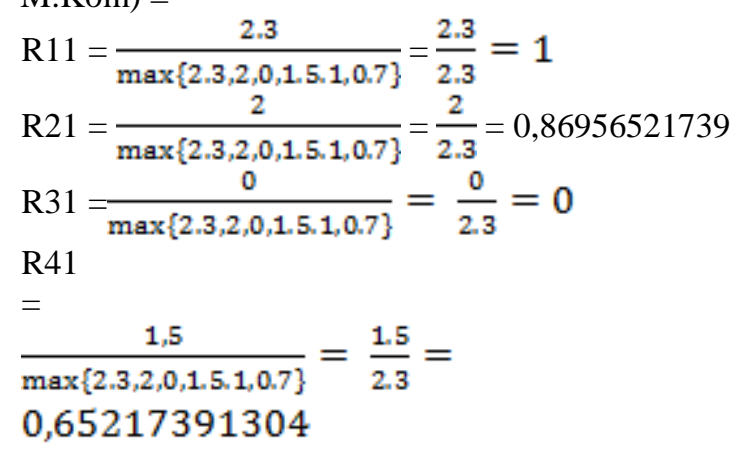

R51

$=$
$\begin{aligned} & \max \{2.3,2,0,1,5,1,0.7\} \\ & 0,4347826087\end{aligned}=\frac{1}{2.3}=$

R61

$=$

\begin{tabular}{cccccccc}
\multicolumn{8}{c}{ Tabel 10 Hasil Seleksi Proposal } \\
\hline $\begin{array}{c}\text { Nama } \\
\text { Penerima } \\
\text { Hibah }\end{array}$ & C1 & C2 & C3 & C4 4 & C5 & C6 & Notal \\
\cline { 2 - 7 } Nilai & \\
\hline (A1) & 2,33333 & 2 & 0 & 1,5 & 1 & 0,66666 & 7,5
\end{tabular}

Normalisasi Matrix Alternatif 2 (A2/Muhammad Yasin Simargolang) $=$

$$
\begin{aligned}
& \mathrm{R} 12=\frac{2.7}{\max \{2.7,3,5,1.5,1.5,1.3\}}=\frac{2,7}{5}=0,54 \\
& \mathrm{R} 22=\frac{3}{\max \{2.7,3,5,1.5,1.5,1.3\}}=\frac{3}{5}=0,6 \\
& \mathrm{R} 32=\frac{5}{\max \left\{2.7,3_{z} 5,1.5,1.5,1.3\right\}}=\frac{5}{5}=1 \\
& \mathrm{R} 42=\frac{1.5}{\max \{2.7,3,5,1.5,1.5,1.3\}}=\frac{1.5}{5}=0,3 \\
& \mathrm{R} 52=\frac{1.5}{\max \{2.7,3,5,1.5,1.5,1.3\}}=\frac{1.5}{5}=0,3 \\
& \mathrm{R} 62=\frac{1.3}{\max \{2.7,3,5,1.5,1.5,1.3\}}=\frac{1.3}{5}=0,26
\end{aligned}
$$

Normalisasi Matrix Alternatif 3 (A3/Rumondang, S.Pi, M.Pi) =

$$
\begin{aligned}
& \mathrm{R} 13=\frac{2.3}{\max \left\{2.33_{z} 3_{n} 5,2.5,1.5,1.7\right\}}=\frac{2.3}{5}=0,46 \\
& \mathrm{R} 23=\frac{3}{\max \{2.3,3,5,2,5,1.5,1.7\}}=\frac{3}{5}=0,6 \\
& \mathrm{R} 33=\frac{5}{\max \{2.3,3,5,2,5,1.5,1.7\}}=\frac{5}{5}=1 \\
& \mathrm{R} 43=\frac{2.5}{\max \{2.3,3,5,2.5,1.5,1.7\}}=\frac{2.5}{5}=0,5 \\
& \mathrm{R} 53=\frac{1.5}{\max \left\{2.33_{z}, 5,25,1.5,1.7\right\}}=\frac{1.5}{5}=0,3 \\
& \mathrm{R} 63=\frac{1.7}{\max \left\{2.3,3{ }_{x} 5,2.5,1.5,1.7\right\}}=\frac{1.7}{5}=0,34
\end{aligned}
$$




\begin{tabular}{cccccccc}
\hline \multirow{8}{*}{$\begin{array}{c}\text { Nama } \\
\text { Penerima } \\
\text { Hibah }\end{array}$} & $\mathrm{C} 1$ & $\mathrm{C} 2$ & $\mathrm{C} 3$ & $\mathrm{C} 4$ & $\mathrm{C} 5$ & $\mathrm{C} 6$ & \multirow{2}{*}{$\begin{array}{c}\text { Total } \\
\text { Nilai }\end{array}$} \\
\cline { 2 - 7 } (A2) & 2,66666 & 3 & 5 & 1,5 & 1,5 & 1,33333 & 15 \\
\hline (A3) & 2,33333 & 3 & 5 & 2,5 & 1,5 & 1,66666 & 16 \\
\hline
\end{tabular}

\section{B. Perancangan}

Dalam perancangan sistem pendukung keputusan penerimaan hibah penelitian dan pengabdian kepada masyarakat bagi dosen Universitas Asahan ini, penulis menggunakan UML (Unified Modelling Language).

\section{Use Case}

Use case merupakan fungsionalitas dari suatu sistem, sehingga user atau aplikasi dapat mengerti mengenai aplikasi yang akan dibangun. Use Case aplikasi dapat dilihat dalam gambar 4.1

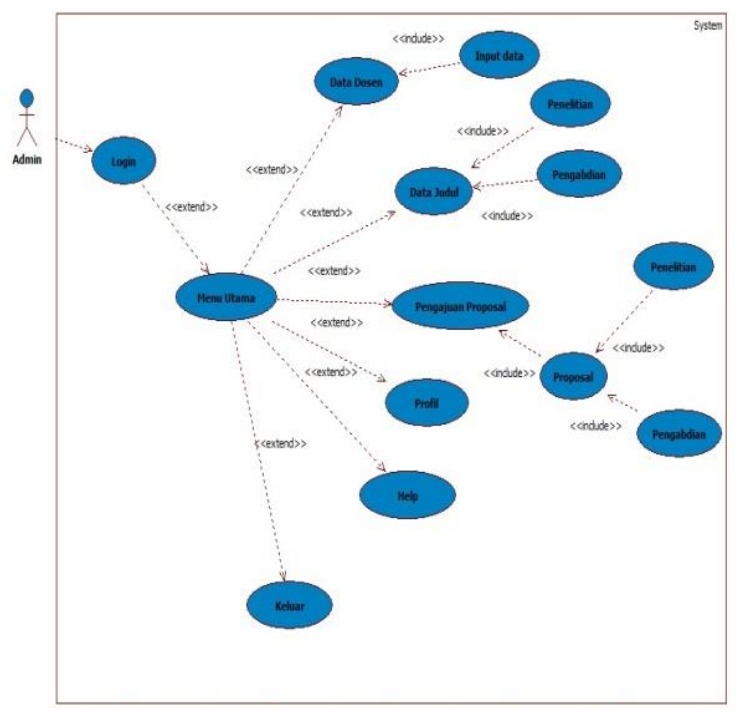

Gambar 2 Implementasi Menu Login

\section{Implementasi Sistem}

Implementasi sistem ialah membawa hasil desain menjadi software. Implementasi dari hasil rancangan sistem sebagai berikut:

\section{$1 \quad$ Menu Login}

Menu login merupakan menu yang pertama kali tampil ketika admin menjalankan aplikasi, pada menu ini admin diharuskan menginputkan username dan password untuk dapat masuk ke menu utama admin, berikut tampilan menu login seperti gambar 2 .

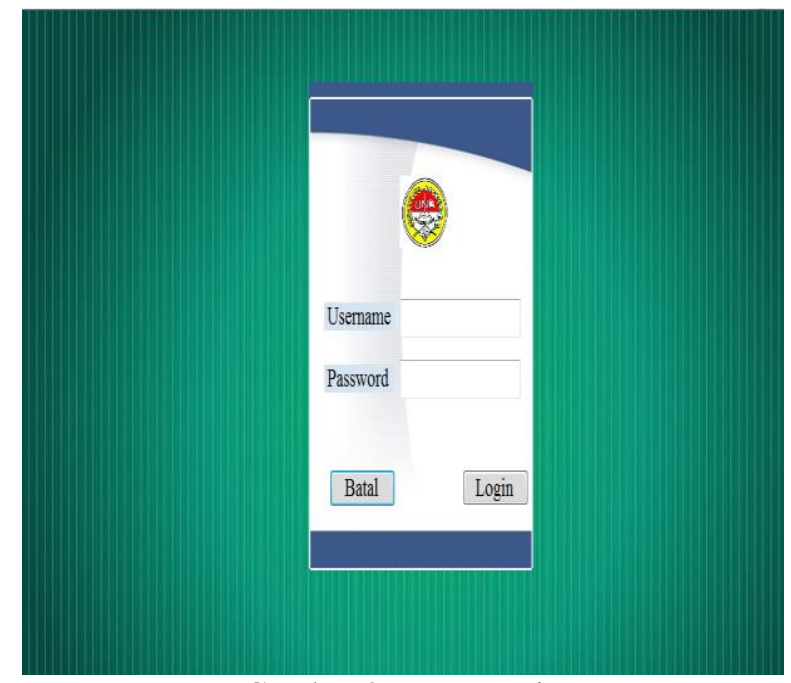

Gambar 2 Menu Login

2 Menu Utama

Menu utama merupakan menu yang pertama kali tampil setelah proses login selesai pada menu ini berisikan menu seperti data dosen, data judul, pengajuan proposal, profi, help menu ini berfungsi sebagai navigasi untuk ke menu yang terdapat pada menu utama, berikut tampilan menu login seperti gambar 3 .

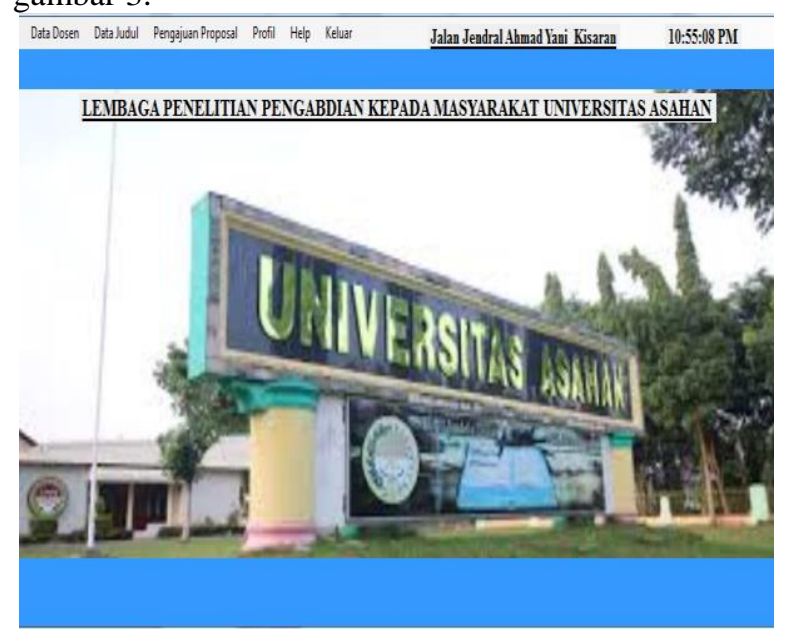

Gambar 3 Menu Utama

\section{Menu Data Dosen}

Menu data dosen merupakan menu yang digunakan untuk mengolah data dosen yang ada di Universitas Asahan, berikut tampilan menu data dosen seperti gambar 4 


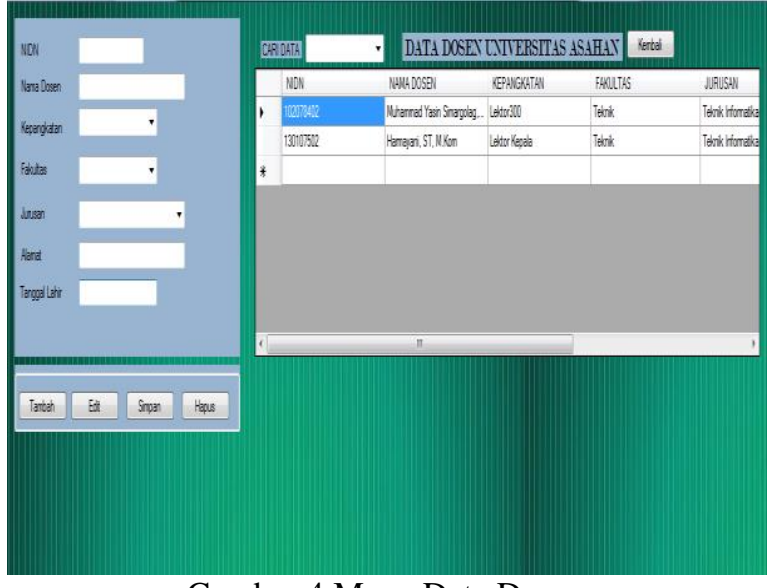

Gambar 4 Menu Data Dosen

$4 \quad$ Menu Judul Penelitian

Menu judul penelitian merupakan menu yang digunakan untuk mengolah judul-judul penelitian dosen yang masuk ke lppm Universitas Asahan agar judul penelitian tidak berulang-ulang masuk ke lppm, berikut tampilan menu judul penelitian seperti gambar 5 .

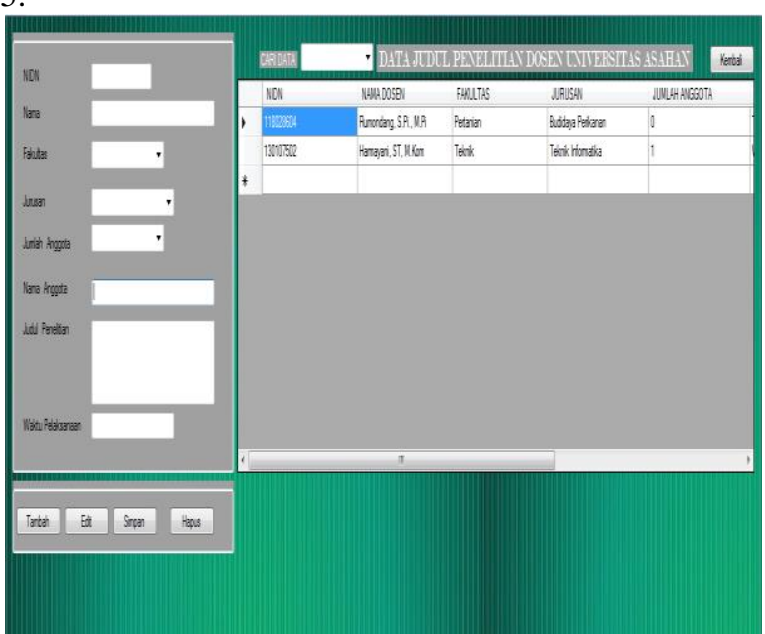

Gambar 5 Menu Judul Penelitian

$5 \quad$ Menu Judul Pengabdian

Menu judul pengabdian merupakan menu yang digunakan untuk mengolah judul-judul pengabdian kepada masyarakat dosen yang masuk ke lppm Universitas Asahan agar judul pengabdian tidak berulang-ulang masuk ke lppm, berikut tampilan menu judul pengabdian seperti gambar 6 .

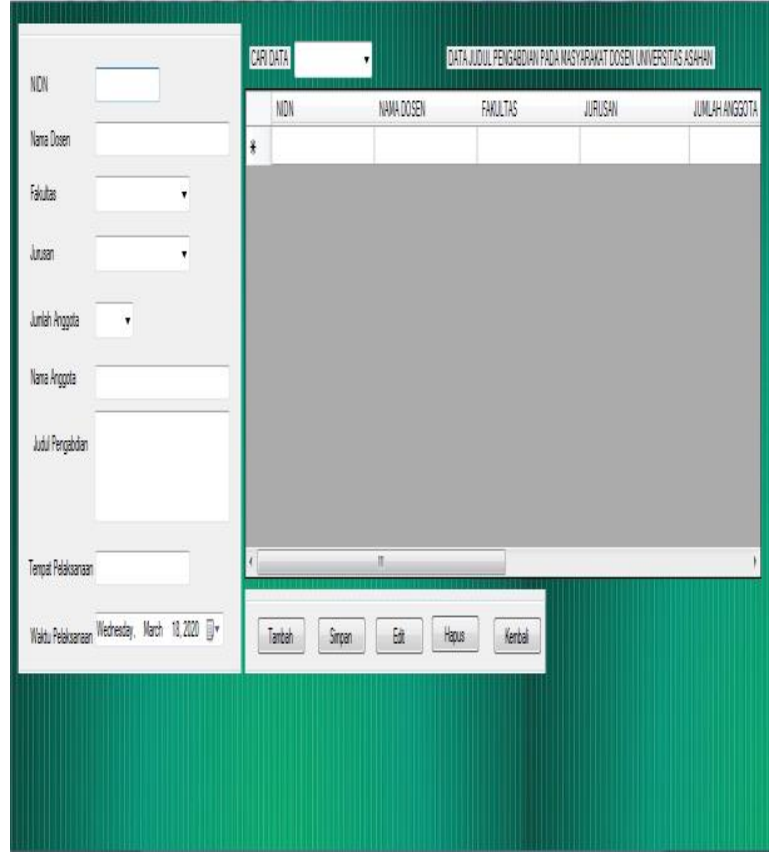

Gambar 6 Menu Judul Pengabdian

6 Menu Pengajuan Proposal

Menu pengajuan proposal merupakan menu yang digunakan untuk menseleksi proposal yang masuk ke lppm dengan penilaian keriteria yang ada pada isi proposal, berikut tampilan menu pengajuan proposal seperti gambar 7

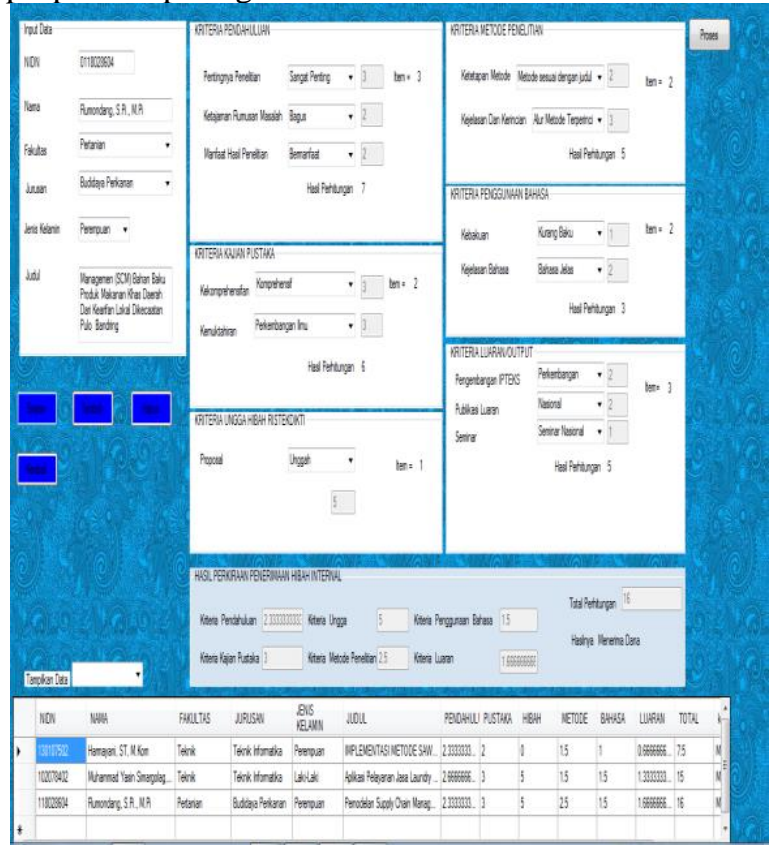

Gambar 7 Menu Pengajuan Proposal

$7 \quad$ Menu Profil

Menu profil merupakan menu yang digunakan untuk melihat keterangan tentang LPPM, berikut tampilan menu profil seperti gambar 8 . 


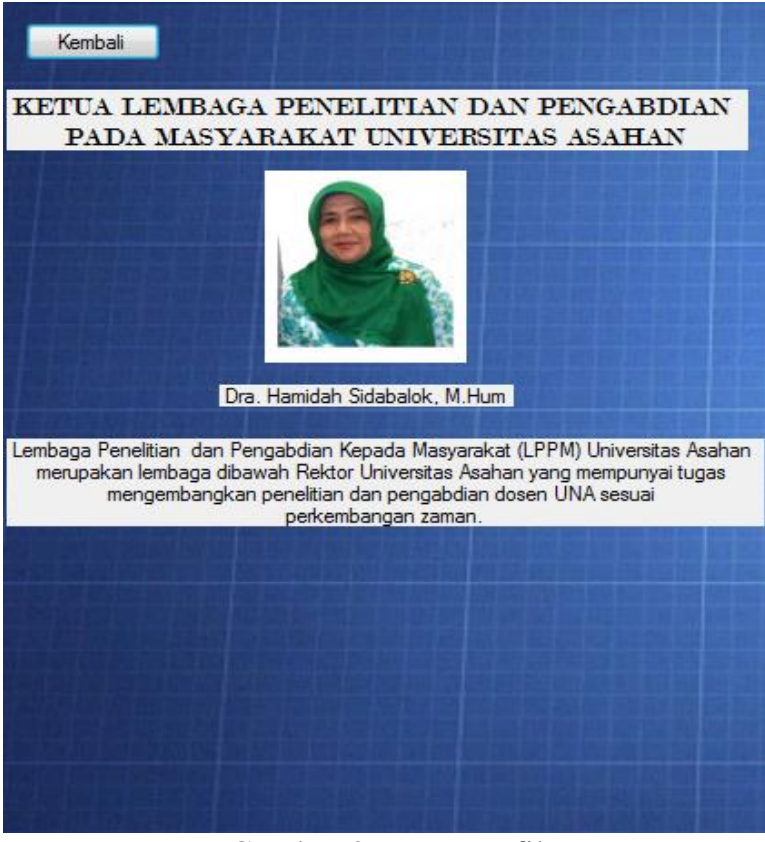

Gambar 8 Menu Profil

$8 \quad$ Menu Help

Menu help merupakan menu yang digunakan untuk memberikan panduan cara menggunakan aplikasi ini, berikut tampilan menu help seperti gambar 9.

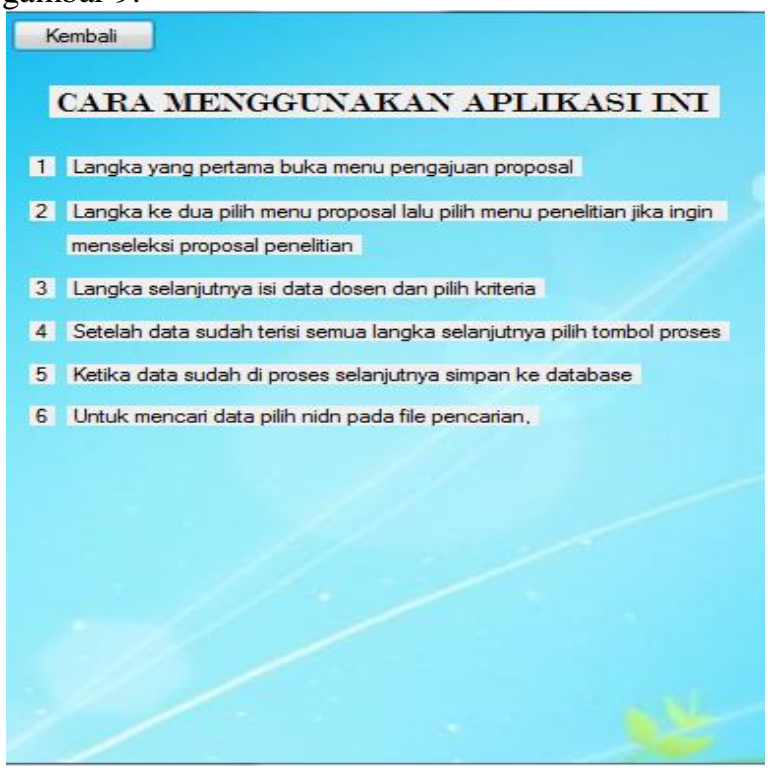

Gambar 9 Menu Help

\section{KESIMPULAN}

Dari hasil pembahasan pada bab-bab yang telah diuraikan sebelumnya, maka penulis mengambil kesimpulan sebagai berikut :
1. Dalam merancang Aplikasi pendukung keputusan penerimaan hibah penelitian dan pengabdian kepada masyarakat bagi dosen Universitas Asahan peneliti merancangnya sesuai kebutuhan yang ada, dengan beberapa menu yang digunakan untuk mengolah data judul penelitian dan pengabdian selanjutnya di seleksi berdasarkan ketentuan.

2. Dalam menerapkan metode SAW pada sistem pendukung keputusan penentuan penerima dana hibah internal peneliti menerapkan algoritma perhitungan dari tiap-tiap keriteria seperti kriteria pendahuluan, kriteria kajian pustaka, kriteria ungga ristekdikti, kriteria metode penelitian, kriteria bahasa dan kriteria luaran dari hasil perhitungan didapat lah suatu keputusan berhak atau tidaknya dosen mendapatkan bantuan.

3. Untuk mengatasi masalah yang terjadi saat ini pada penentuan seleksi penerimaan dana hibah internal yang ada di Universitas Asahan dengan cara keterbukaan dalam menyampaikan informasi terkait seleksi hibah internal dan melakukan penilaian terhadap proposal yang masuk sehingga tidak adanya keraguan terhadap dosen.

\section{DAFTAR PUSTAKA}

[1] A.B. Ladjamudin, Analisis Dan Desain Sistem Informasi, GRAHA ILMU Yogyakarta, 2015.

[2] B. Prasetyo, et al, "Perancangan dan Pembuatan Sistem Informasi Gudang (Studi Kasus : PT. PLN (Persero) Area Surabaya Barat)". TEKNIKA. Vol. 4. No. 1. 2015.

[3] R. Yesputra, "Belajar Visual Basic. Net Dengan Visual Studio 2010". Penerbit : Royal Asahan Press. 2017.

[4] Harmayani, (2019). PRODUKSI KOPRA MENJADI SANTAN BUBUK DENGAN METODE SIMPLE ADDITIVE WEIGHTING ( SAW ) Fakultas Teknik Jurusan Teknik Informatika Universitas Asahan. 5, 42-50. 